
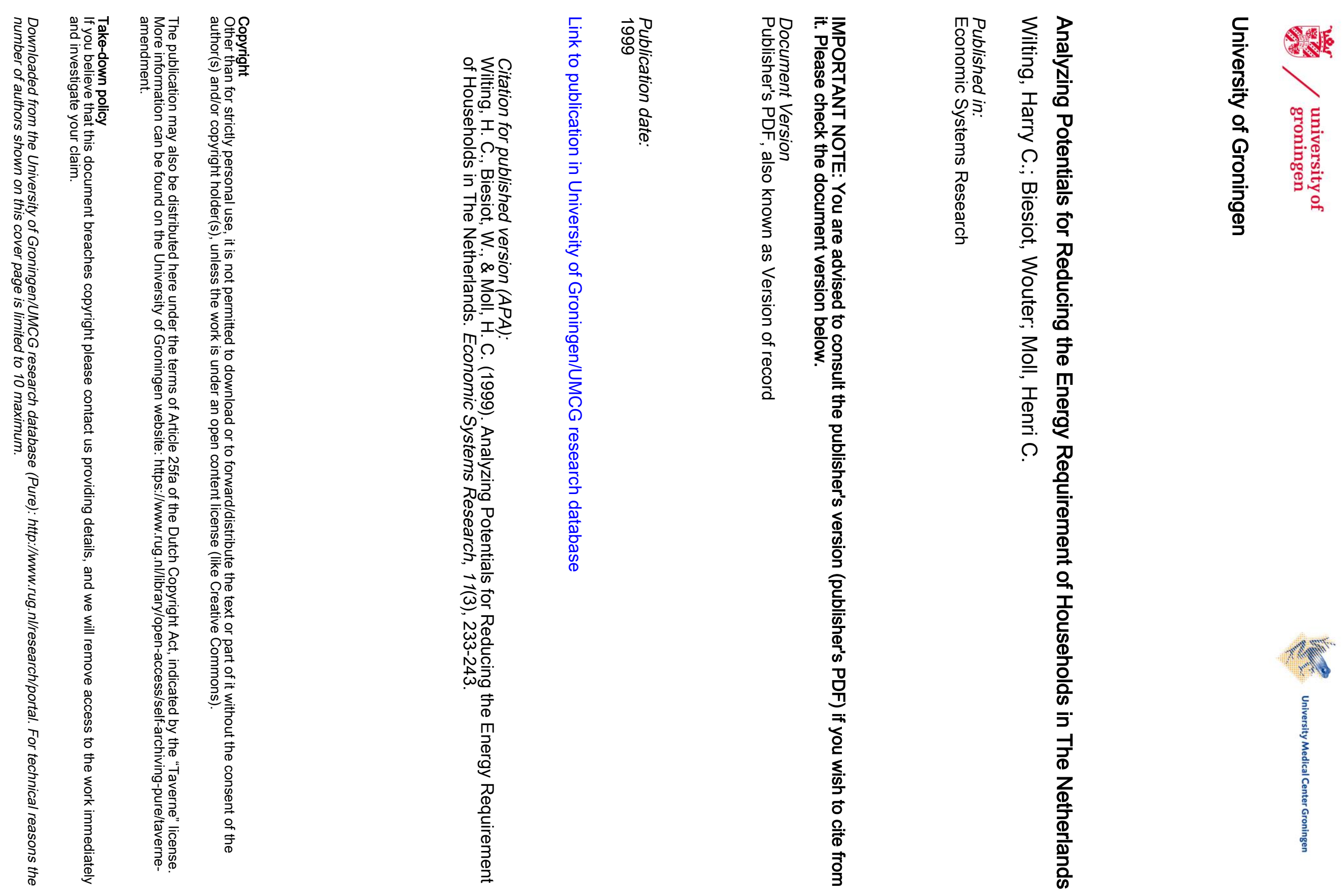


\title{
Analyzing Potentials for Reducing the Energy Requirement of Households in The Netherlands
}

\author{
HARRY C. WILTING, WOUTER BIESIOT \& HENRI C. MOLL
}

(Received April 1998; revised fanuary 1999)

\begin{abstract}
The energy requirement of households represents a useful concept in studying energy use in relation to production structures and consumption patterns. Reduction potentials of the energy requirement for households provide insight on the possibilities for reducing energy use in the whole economy. We determine reduction potentials by means of implementing energy conservation options in an input-output model for calculating the household energy requirement. The implementation of a set of technical energy conservation options results in a reduction in the energy requirement of Dutch households by $55 \%$. The reduction potential based on a set of demand-side options is $9 \%$. The combination of both sets of conservation options results in a reduction potential of 59\%. Therefore, by combining (sets of) options, some effects are cancelled out.
\end{abstract}

KeYwords: Energy conservation, households, The Netherlands

\section{Introduction}

At present, $90 \%$ of the world's commercial energy use originates from fossil fuels, such as coal, oil and natural gas (IEA, 1996). Energy use based on fossil fuels leads to important environmental drawbacks, such as the risk of an enhanced 'greenhouse' effect and environmental degradation at the mining sites of fossil fuels. Furthermore, with the current growth rate of energy use, the depletion of easily accessible fossil energy resources will probably become a reality at some point in the next century (Mulder \& Biesiot, 1998). A first step towards more sustainable energy use is energy conservation. Traditionally, energy conservation drives started from a technological view. Although technological energy conservation measures lead to reasonable savings in energy use per unit product, these savings are often cancelled out by the ongoing growth in consumption. Therefore, interest in lifestyles and consumption patterns as a second source for energy conservation has grown (Bruggink, 1995).

In studying energy use in relation to consumption patterns, the concept of the

Harry C. Wilting, Center for Energy and Environmental Studies IVEM, University of Groningen, Nijenborgh 4, NL-9747 AG Groningen, The Netherlands. Fax: + 31503637168 ; E-mail: Harry. Wilting@rivm.nl. The authors gratefully acknowledge Ton Schoot Uiterkamp, Erik Dietzenbacher and an anonymous referee for their helpful comments, and the Dutch National Research Programme on Global Air Pollution and Climate Change for the financial support. 
energy requirement of households is useful (Biesiot \& Moll, 1995; Vringer \& Blok, 1995). Households can be seen as end-users of goods produced and services delivered by economic production sectors. Energy use along entire production chains of products and services can be attributed to items of household consumption patterns. The energy requirement of households comprises the energy used in the life cycles of all consumption items. Therefore, by focusing on household consumption patterns, energy use in households and in production sectors can be studied. Energy analysis provides methods for calculating the energy requirement of households. The main energy analysis methods are process analysis and inputoutput (IO) analysis (IFIAS, 1974).

Process analysis has its origins in engineering, and uses a description in physical terms of the life-cycle processes of consumption items. Next, the energy use in all processes is determined in detail. Process analysis is an accurate, albeit laborious method, so is less appropriate for calculating the household energy requirement. IO analysis uses economic IO tables for the determination of energy use in production chains of consumption items. Since undertaking an IO analysis takes much less time, it is a convenient methodology for the determination of energy use associated with consumption patterns. However, the accuracy of the outcomes depends on the aggregation level of the IO tables used. By now, hybrid analysis methods have been developed to combine the best elements of process analysis and IO analysis (Bullard et al., 1978; van Engelenburg et al., 1994; Treloar, 1997).

The possibilities for energy conservation can be investigated from an industrial perspective (efficiency improvements and substitution) and from a household perspective (efficiency improvements, substitution and demand-side options). Analysis of the household energy requirement provides an integral perspective to consider energy conservation in the whole economy (imports and exports excluded). In The Netherlands, the effects of individual technical and demandside energy conservation options on the energy requirement of Dutch households have been calculated previously, by using a hybrid energy analysis method (Kramer et al., 1994; Noorman et al., 1998; Vringer et al., 1995). We investigate the potential for reducing the Dutch household energy requirement, by implementing energy conservation options in an IO model for calculating the household energy requirement. In order to illustrate the methodology, first, the effects of individual - both technical and demand-side-energy conservation options are calculated. Then, the combined effect of the options is calculated in order to determine an overall reduction potential of the energy requirement of Dutch households, considering these options.

\section{Calculation of the Energy Requirement of Households}

Households use energy not only in a direct way, such as by using electricity, motor fuels and natural gas, but also in an indirect way, by buying goods (food products, clothes, etc.) and using services (insurances, public transport, etc.). The manufacturing and delivery of these goods and services require energy in economic production sectors. Thus, the energy use of manufacturing and service industries can be considered as indirect energy use of households. Figure 1 shows the distinction between direct and indirect energy use of households. Primary energy derived from fossil sources, such as crude oil, coal and natural gas, flows via production sectors to households. The household energy requirement, which is defined as the total, i.e. direct plus indirect, energy use of households, can be 


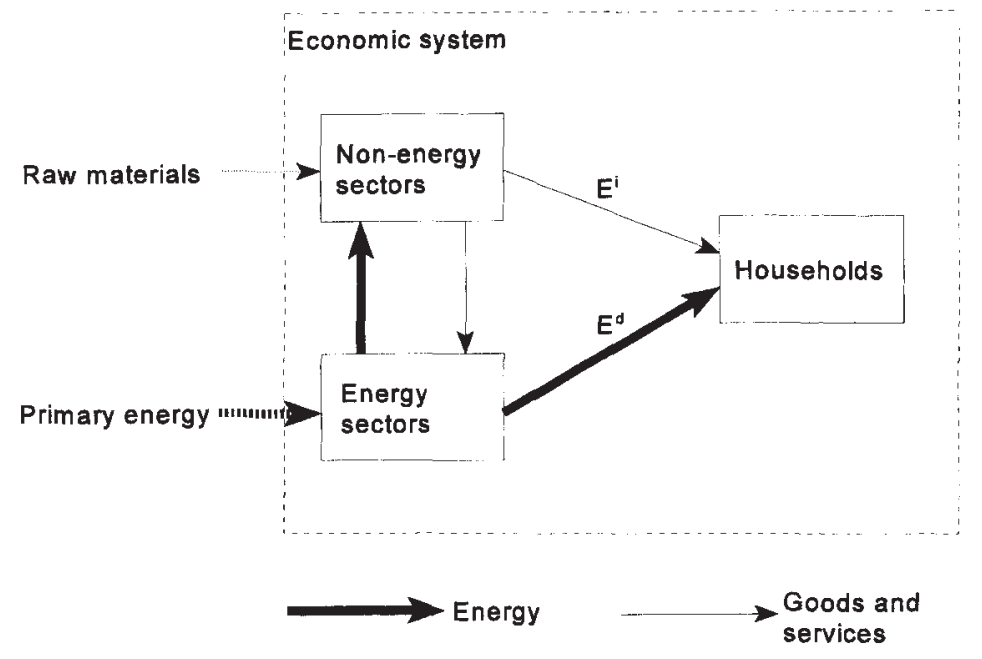

Figure 1. Direct $\left(E^{\mathrm{d}}\right)$ and indirect $\left(E^{\mathrm{i}}\right)$ energy requirement of households.

determined with IO analysis. Wilting (1996) gives an overview of the IO methodology for calculating the energy requirement of households. Generally, the household energy requirement $E$ is determined by using the following static open IO output model:

$$
E=\mathbf{p}^{\prime}(\mathbf{I}-\mathbf{A})^{-1} \mathbf{y}
$$

where $\mathbf{p}$ is an $(n \times 1)$ vector with primary energy input coefficients for each of the $n$ production sectors; $\mathbf{I}$ is the $(n \times n)$ identity matrix; $\mathbf{A}$ is the $(n \times n)$ technological matrix; and $\mathbf{y}$ is an $(n \times 1)$ vector with household consumption per sector.

The primary energy input coefficient $p_{j}$ of sector $j$, depicts the direct primary energy use in physical units required for one monetary unit of production in sector $j$. The energy input coefficient of sector $j$ is calculated by dividing the primary energy use of sector $j$ by the total production of sector $j$.

In IO analysis, it is assumed that monetary transactions in $\mathrm{IO}$ tables are proportional to physical transactions. Since there are large differences in energy prices per sector, this assumption is certainly not valid for energy deliveries. To solve this problem, ${ }^{1}$ for each non-energy production sector and for households, we computed primary energy use on the basis of final energy use, obtained from energy statistics, and energy requirement of energy (ERE) values of energy carriers. The ERE value of an energy carrier gives the total amount of energy needed for the production of that energy carrier. For example, Wilting (1996) calculated for the Dutch 1990 ERE value of electricity - which depends on fuel mix and efficiencies in power stations - a value of 2.75 megajoules per megajoule $(\mathrm{MJ} / \mathrm{MJ})$. This value accounts for energy use during extraction, transport and conversion of fossil fuels, and the distribution of electricity. Since, in our approach, the energy use of the energy sectors is assigned directly to the non-energy production sectors and the households by using ERE values, we have to set the energy use of the energy sectors to zero to avoid double counting (van Engelenburg et al., 1991). The procedure leads to the following static open IO model for the calculation of the household energy requirement:

$$
E=\mathbf{r}^{\prime} \mathbf{D}^{\prime}(\mathbf{I}-\mathbf{A})^{-1} \mathbf{y}+\mathbf{r}^{\prime} \mathbf{d}
$$


where, $\mathbf{r}$ is an $(m \times 1)$ vector with ERE values for each of the $m$ energy carriers; ${ }^{2}$ $\mathbf{D}$ is an $(n \times m)$ matrix with energy input coefficients of production sectors for each energy carrier (energy input coefficients of energy sectors are set to zero); $\mathbf{d}$ is an $(m \times 1)$ vector with direct energy use of households for each energy carrier.

The right-hand side of equation (2) deals with the separate actors in Figure 1. The vector $\mathbf{r}$ corresponds to the conversion of energy in the energy sectors; part $\mathbf{D}^{\prime}(\mathbf{I}-\mathbf{A})^{-1}$ corresponds to the energy use and production structure of the production sectors; and the vectors $\mathbf{y}$ and $\mathbf{d}$ correspond to the consumption pattern and energy use of households respectively. Now, $\mathbf{r}^{\prime} \mathbf{D}^{\prime}(\mathbf{I}-\mathbf{A})^{-1} \mathbf{y}$ can be seen as the indirect energy requirement $E^{i}$, and $\mathbf{r}^{\prime} \mathbf{d}$ can be seen as the direct energy requirement $E^{\text {d }}$ of households.

Intermediate goods and services used in production processes partially concern imports that require energy abroad. The IO table, which was used, distinguishes between competitive and non-competitive imports. Competitive imports concern products that are also produced domestically, unlike non-competitive imports, which are not domestically produced. Competitive imports were assumed to have production structures abroad similar to the production structure in The Netherlands. ${ }^{3}$ In determining the energy requirements of non-competitive imports, we used additional information on the production structures of these goods abroad and on input structures of comparable sectors.

The household energy requirement also allows for energy required for producing capital goods in the past. The energy requirements of capital goods in a sector were distributed over the whole economic lifetime of the capital goods. The annual contribution of energy (as embodied in the capital goods) to production was determined using the depreciation of these capital goods. In order to account for the energy requirements of capital goods, we extended the IO table with an extra row and column. The row comprises the annual depreciation for all sectors; the column comprises the input structure of the capital goods. Since no information on the composition of the capital goods in the past was available, we based this composition on the structure of the new investments in the economy, which was obtained from the final demand section of the IO table.

\section{Calculating Reduction Potentials of the Household Energy Requirement}

The calculation of the reduction potentials of the household energy requirement in relation to a set of options requires a precise representation of the changes in the IO model. First, we discuss the composition of the set of energy conservation options considered. Energy conservation options are available at the level of individual actors. Some of these options affect energy use in one or more production sectors; other options affect the energy use in households. Examples of energy conservation options are as follows:

- improvements in energy efficiency at conversion and end-use of energy;

- shifts to expenditures with lower energy requirements;

- substitution of raw materials;

- a more efficient and economical use of raw materials;

- an increase in the productivity of labour or capital;

- good housekeeping.

Energy conservation options may have a technological or a behavioural character, 


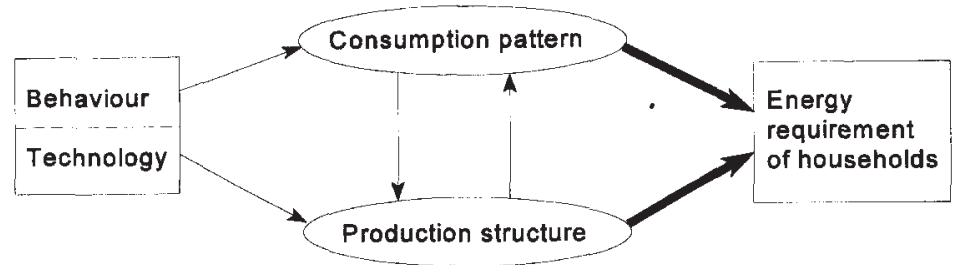

Figure 2. Relations between technological and behavioural changes and the energy requirement of households.

although the distinction between technology and behaviour is not always clear. Washing clothes using a more economical washing machine is a technological option, although the choice for producing or purchasing a more efficient washer is a behavioural choice. Technological and behavioural changes may influence the production structure and the consumption pattern, both directly and indirectly (see Figure 2). The consumers' decision to use the launderette instead of washing at home not only affects consumption patterns, but also production. The number of launderettes will grow, the production of washers will decrease, etc. However, more efficient production methods may influence the prices at which the products are purchased. In turn, such price effects may change the consumption pattern.

The effects of energy conservation options on energy use differ between options. An improvement in energy efficiency in a certain sector decreases energy use in that sector. A shift in consumption to a less energy-intensive product may change energy use in several production sectors-even in other countries. An investigation of the combined effect of various energy conservation options is of interest, since this effect is not clear beforehand. The combined effect of a set of reduction options may be lower than the sum of the effects of the individual options. For example, technical energy conservation options in greenhouse horticulture may decrease the energy requirements of vegetables considerably. The same holds for a shift from greenhouse vegetables to seasonal outdoor vegetables. However, the effect of combining both options will be less than the sum of the effects of the individual options.

Each energy conservation option corresponds to changes in one or more elements of the five parameters of the IO model. Technological options that concern energy efficiency improvements in both conversion and end-use of energy are implemented in the IO model by changing the parameters $\mathbf{r}, \mathbf{D}$ and $\mathbf{d}$. Options that concern changes in production processes in order to save energy, such as through substitution of materials or changes in productivity, are implemented in the IO model via parameter A. As an example, Figure 3 shows the elements in the parameters $\mathbf{A}$ and $\mathbf{y}$ which are changed as a result of a reduction option that concerns a shift from plastic to wooden furniture. The coefficients in the production column of furniture that correspond to the use of plastics and wood are changed. Furthermore, the consumption of furniture may change as a result of price differences between plastic and wooden furniture, and also because the lifetime of wooden furniture is likely to be longer. The implementation of changes in the consumption pattern of households in the model is performed via the parameter y. However, in practice, demand-side options may also affect other parameters, such as $\mathbf{d}$ and $\mathbf{A}$. Reduction potentials are determined by implementing sets of energy conservation options in the IO model, by making changes in several elements 


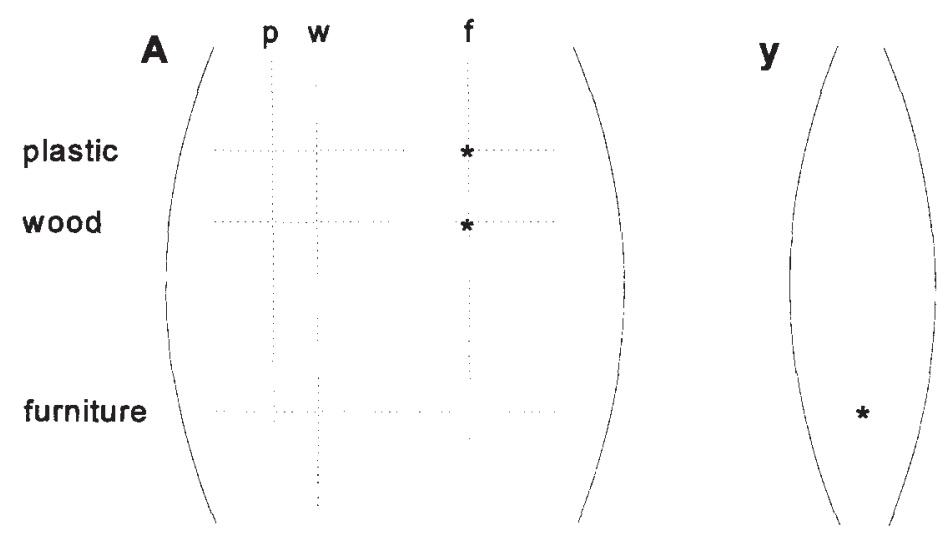

Figure 3. Elements of the technological matrix $\mathbf{A}$ and the consumption vector $\mathbf{y}$ that are changed in the case of a shift from plastic to wooden furniture.

of the five model parameters simultaneously. The combined effect of all individual options determines the overall reduction potential of the household energy requirement with regard to the given set of options.

Considering the level of detail of the energy conservation options, the IO tables used should be at a low aggregation level. Therefore, we used a socalled 'homogeneous' IO table for our investigations. The rows and columns in homogeneous IO tables correspond to commodities which can be seen as collections of goods which are produced as much as possible in the same way. The column that corresponds to a commodity can be seen as a representation of the production process of that commodity. Konijn (1994) gives an extensive description of the compilation of homogeneous IO tables on the basis of 'make and use' tables. The first homogeneous table for The Netherlands was compiled for 1987. However, the Dutch Bureau of Statistics (CBS) has now published a homogeneous IO table for 1990 (Konijn \& de Boer, 1993). The homogeneous table that was used consists, for example, of separate rows and columns for plastic and wooden furniture. The shift from plastic to wooden furniture is implemented by changing two elements in the consumption vector $\mathbf{y}$.

\section{Reduction Potentials of the Energy Requirement of Households in The Netherlands}

We illustrate the methodology by calculating the effect that conservation options described in the literature have on the household energy requirement. We obtained technical energy conservation options from a database, called ICARUS, containing data on several hundred technical energy conservation measures of all production sectors and of households realizable in a period of 25 years (de Beer et al., 1994). These technical energy conservation measures take into account the expected improvements in technology. A set of 20 demand-side energy conservation options was obtained from Vringer et al. (1993), Brouwer (1998), Kramer (1998) and Vringer et al. (1999). These reduction options concern shifts between consumption categories and within consumption categories.

The household energy requirement in 1990 served as a starting point in the calculations, since that year is the most recent year for which detailed IO tables are 


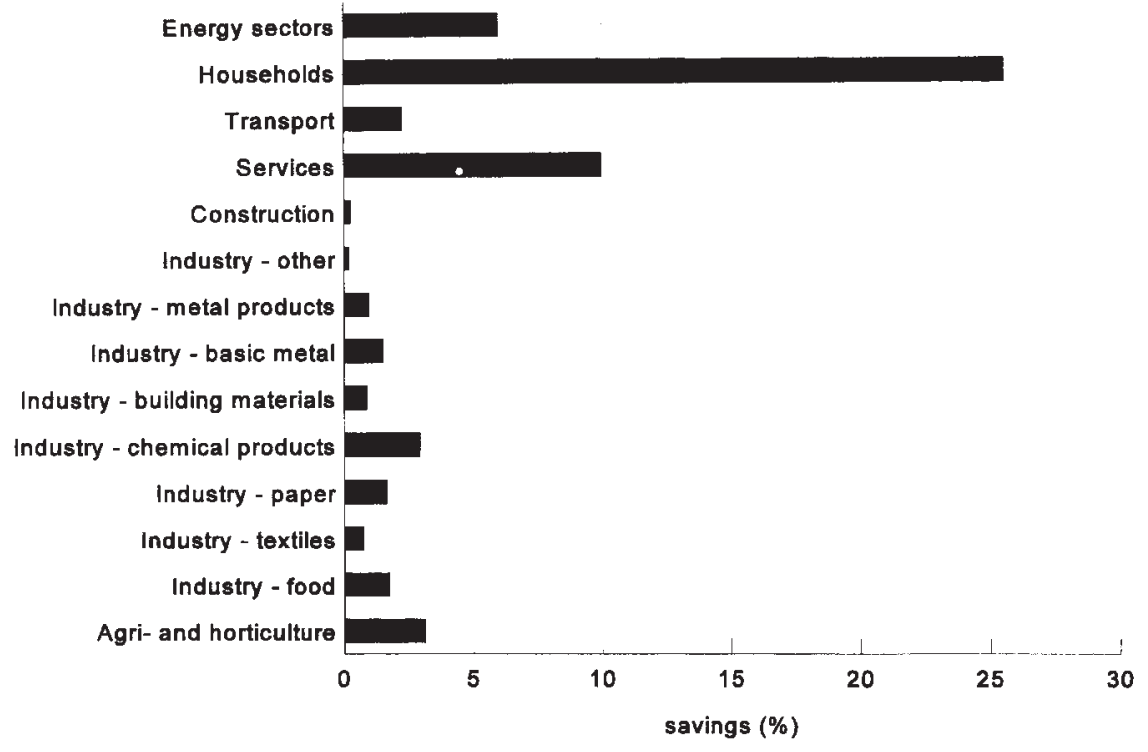

Figure 4. Savings in the 1990 energy requirement of households in The Netherlands, as a result of implementing technical energy conservation options in production sectors and households.

available. The 1990 household energy requirement, calculated using equation (2), is 1731 petajoules (PJ), of which $707 \mathrm{PJ}(41 \%)$ is related to direct energy use in the households itself. We determined the reduction potential of the energy requirement of households in 1990, by implementing the energy conservation options mentioned. The technological options from the ICARUS database were implemented in the model via the parameters $\mathbf{r}, \mathbf{D}$ and $\mathbf{d}$. Figure 4 gives an overview of the savings in the household energy requirement, that result from technological improvements in production sectors and households. The savings are clustered per sector or group of sectors. For instance, the savings in the household energy requirement, as a result of implementing all available options in the industrial food sectors, are almost $2 \%$. Examples of options in the food sectors are a more efficient evaporation process in the dairy industries or, in the sugar industries, an improved beet pulp drying process. The combined application of all technological options from the ICARUS database results in a $55.0 \%$ decrease in the 1990 household energy requirement. Almost half the savings can be attributed to households themselves-more efficient houses, appliances and private cars. The other savings are mainly accomplished by measures in the industrial and service sectors. Figure 4 also shows the effect of measures in the energy sectors, such as improvements in efficiency in electricity production, on the household energy requirement. These savings $(5.9 \%)$ concern savings in energy sectors without the implementation of measures in other sectors.

The demand-side options used concern several household consumption categories: food, clothing and maintenance of clothing, household effects, recreation, holidays and transport. For each demand-side option, the corresponding parameters in the model were adapted. Figure 5 shows the individual effects of the demand-side options on the 1990 energy requirement of households in The Netherlands. For example, among all households that possess a car, if cars are 


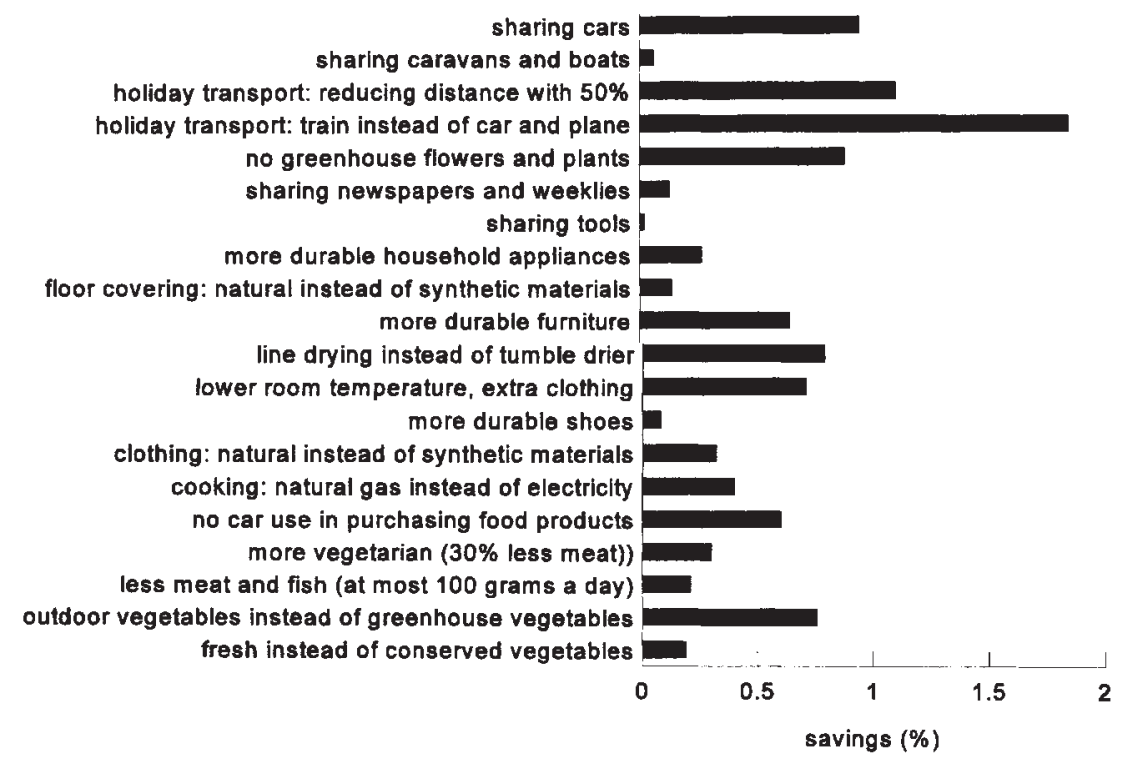

Figure 5. Savings in the 1990 energy requirement of households in The Netherlands, as a result of implementing demand-side energy conservation options.

shared by two households, then less cars have to be produced. The decreased purchase of cars results in a saving in the household energy requirement of almost $1 \% .{ }^{4}$ Options which result in more than $1 \%$ reduction in the household energy requirement are in the category of holidays. Other large-saving options concern the replacement of greenhouse products, such as flowers and vegetables. The sum of the individual savings for the 20 demand-side options listed in Figure 5 is $10.4 \%$. The combined implementation of the demand-side energy conservation options resulted in a $9.3 \%$ reduction in the household energy requirement, since there is some interrelationship among the options. The reduction potential based on combining both technological and demand-side options is $59.2 \%$. Since this figure is somewhat smaller than the sum of the savings based on both sets separately-which is $64.4 \%$ - the combined effect of options is diminished. The household energy requirement decreases to $780 \mathrm{PJ}$. Since most conservation options concern direct energy use in the households, the share of the direct energy requirement in the total energy requirement of households decreases from $41 \%$ to $33 \%$.

\section{Discussion}

The research described in this paper is a first step in investigating the reduction potentials of the energy requirement of households by using IO analysis. The IO approach is an extension of earlier research on reduction potentials, since the IO framework enables an easier investigation of sets of reduction options. The use of IO analysis also enables (future) research directed towards examining the effects of energy conservation options on several economic parameters. The implementation of the demand-side energy conservation options particularly affects the economy, 
such as the size of economic sectors, GDP and employment. The evaluation of several individual energy conservation options may result in a ranking of energy conservation options that concern the effect on energy use and economic parameters. The outcome of such considerations clarifies the social significance of separate energy conservation options.

The reduction potential of the household energy requirement depends on the set of energy conservation options used. In particular, the choice of demand-side options, such as the reduction of holiday transport $(50 \%)$ or the reduction of meat consumption (30\%), is arbitrary. Reduction potentials may be determined for different sets of options, such as a moderate set against a more extreme set of options. The choice of a set of reduction options may be based on the economic feasibility of technical energy conservation options, or on the willingness of households to accept shifts in consumption. In choosing a set of demand-side options, other household constraints, such as time and money, have to be taken into account. The methodology does not give directions on how to implement the energy conservation options in practice.

The approach described is generally applicable but, considering the easy access to data, The Netherlands was taken as an example. Therefore, we restricted ourselves to the energy requirement of Dutch households. The energy requirement does not correspond to energy use in The Netherlands. Energy use in the economic production sectors also involves exports and investments, for example. Conversely, in other countries, energy is used for the production of goods and services for Dutch households. Therefore, the reduction potential of Dutch energy use will be different from that of the household energy requirement.

The calculations concerning the reduction potentials assume (except for the implementation of the options) no further changes in 1990 production and consumption patterns. In investigating the future household energy requirement, it is more realistic to allow for expected economic and demographic developments. Therefore, investigations of reduction potentials should be combined with so-called 'scenario studies' on the future household energy requirement, as carried out by Proops et al. (1992), and Weber et al. (1996), for example. The reduction potential of an 'extreme' set of options can be seen as an upper bound for the possible outcomes of the different scenarios. Wilting et al. (1998) carried out such an approach by relating energy conservation options to an economic scenario for the period 1995-2020.

The present case study demonstrated IO analysis as a tool for determining reduction potentials on the basis of sets of known energy conservation options. IO analysis can also be used in the search for further energy conservation options. By using sensitivity analysis, it is possible to identify model elements which markedly affect the household energy requirement. For example, a sensitivity analysis that concerned the elements in the technological matrix $\mathbf{A}$ might indicate production processes which have a relatively high share in the household energy requirement. Sectors, processes, expenditures, etc., that correspond to the important elements are relevant for the total household energy requirement. Important sectoral contributions to the household energy requirement can also be identified, by applying the methodology developed by Weber and Schnabl (1998) for the identification of important contributions to the total energy requirements of products. The identification of important sectors and processes may induce new directions for energy research and policy. 


\section{Conclusions}

We have presented a methodology to investigate the reduction potentials of the energy requirement of households. The methodology implements sets of energy conservation options in an IO model for the calculation of the energy requirement of households. These sets are based on both technical and demand-side energy conservation options. The case study concerning the reduction potentials for the Dutch household energy requirement showed the applicability of the methodology.

The case study showed that the implementation of technological and of demandside energy conservation options may bring about a reasonable reduction in the household energy requirement. The implementation of known technological options reduces the household energy requirement by $55 \%$. The implementation of the set of demand-side options results in a decrease of $9 \%$. The combined effect of both types of option is smaller than the sum of the effects of the separate options. Obviously, there exist some interrelationships between some of the energy conservation options. Since the set of energy conservation options considered has more impact on the direct energy requirement than on the indirect energy requirement, the share of the direct energy requirement in the total household energy requirement declines from $41 \%$ to $33 \%$.

\section{Notes}

1. Another solution for this price problem is the use of hybrid, i.e. mixed monetary-energy, models as described by Bullard and Herendeen (1975).

2. In our calculations, we distinguished four groups of energy carriers, i.e. coal and coal products, oil and oil products, natural gas and electricity.

3. Recently, Battjes et al. (1998) showed that there are differences in sectoral energy intensities, depicting total energy requirement per monetary unit, per country.

4. We assumed that the annual number of kilometres per household does not change. Therefore, this option only concerns indirect energy use of households.

\section{References}

Battjes, J. J., Noorman, K. J. \& Biesiot, W. (1998) Assessing the energy intensities of imports, Energy Economics, 20, pp. 67-83.

de Beer, J. G., van Wees, M. T., Worrell, E. \& Blok, K. (1994) ICARUS-3: The Potential of Energy Efficiency Improvement in The Netherlands up to 2000 and 2015, Research Report No. 94013 (Utrecht, NW\&S, Utrecht University).

Biesiot, W. \& Moll, H. C. (eds) (1995) Reduction of $\mathrm{CO}_{2}$ Emissions by Lifestyle Changes, Final Report to the NRP Global Air Pollution and Climate Change, IVEM Research Report No. 80 (Groningen, University of Groningen).

Brouwer, N. M. (1998) Energy Reduction Options Related to Dutch Household Food Consumption, Working Paper (Wageningen, Wageningen Agricultural University).

Bruggink, J. J. C. (ed.) (1995) Energy Demand, Life Style Changes and Technology Development, Research Report No. RX-95-042 (Petten, Netherlands Energy Research Foundation ECN).

Bullard, C. W. \& Herendeen, R. A. (1975) The energy costs of goods and services, Energy Policy, 3, pp. 484-493.

Bullard, C. W., Penner, P. S. \& Pilati, D. A. (1978) Net energy analysis: Handbook for combining process and input-output analysis, Resources and Energy, 1, pp. 267-313.

van Engelenburg, B. C. W., van Rossum, T. F. M., Blok, K., Biesiot, W. \& Wilting, H. C. (1991) Energiegebruik en Huishoudelijke Consumptie: Handleiding en Toepassingen, Research Report No. 91032 (Utrecht, NW\&S, Utrecht University) (in cooperation with IVEM, University of Groningen).

van Engelenburg, B. C. W., van Rossum, T. F. M., Blok, K. \& Vringer, K. (1994) Calculating the energy requirements of household purchases, Energy Policy, 22, pp. 648-656.

IEA (1996) World Energy Outlook (Paris, International Energy Agency/OECD). 
IFIAS (1974) Energy Analysis: Workshop on Methodology and Conventions, Report No. 6 (Stockholm, International Federation of Institutes for Advanced Study).

Konijn, P. J. A. (1994) The Make and Use of Commodities by Industries: On the Compilation of Input-Output Data from the National Accounts, PhD Thesis, University of Twente, Enschede.

Konijn, P. J. A. \& de Boer, S. (1993) Een homogene input-outputtabel voor Nederland, 1990 (Voorburg, Centraal Bureau voor de Statistiek, Hoofdafdeling Nationale Rekeningen).

Kramer, K. J. (1998) Options to Reduce the Energy Use and Greenhouse Gas Emissions Related to Dutch Household Food Consumption, IVEM Working Paper No. 9801 (Groningen, University of Groningen).

Kramer, K. J., Biesiot, W., Kok, R., Wilting, H. C. \& Schoot Uiterkamp, A. J. M. (1994) Energie Geld(t): Mogelijke Energiebesparingen op Huishoudelijke Uitgaven, IVEM Research Report No. 71 (Groningen, University of Groningen).

Mulder, H. A. J. \& Biesiot, W. (1998) Transition to a Sustainable Society: A Backcasting Approach to Modelling Energy and Ecology (Cheltenham, Edward Elgar).

Noorman, K. J., Biesiot, W. \& Moll, H. C. (1998) Changing life styles in transition routes towards sustainable household consumption patterns, paper presented at the Second International Conference of the European Society for Ecological Economics, Geneva, March.

Proops, J. L. R., Faber, M. \& Wagenhals, G. (1992) Reducing $\mathrm{CO}_{2}$ Emissions: A Comparative Input-Output Study for Germany and the UK (Berlin, Springer).

Treloar, G. J. (1997) Extracting embodied energy paths from input-output tables: Towards an input-output-based hybrid energy analysis method, Economic Systems Research, 9, pp. 375-391.

Vringer, K. \& Blok, K. (1995) The direct and indirect energy requirements of households in the Netherlands, Energy Policy, 23, pp. 893-910.

Vringer, K., Potting, J., Blok, K. \& Kok, R. (1993) Onderbouwing Reductiedoelstelling Indirect Energieverbruik Huishoudens, Research Report No. 93073 (Utrecht, NW\&S, Utrecht University) (in cooperation with IVEM, University of Groningen).

Vringer, K., Potting, J., Blok, K. \& Kok, R. (1995) A reduction in the indirect energy requirement of households, in: A Persson (ed.) Proceedings of the 1995 ECEEE Summer Study: Sustainability and the Reinvention of Government-A Challenge for Energy Efficiency (Stockholm, ECEEE).

Vringer, K., Uitdenbogerd, D. E., Potting, J. \& Blok, K. (1999) Energy Reduction Options Related to Dutch Household Textile Maintenance, Working paper (Wageningen, Wageningen Agricultural University) (in cooperation with NW\&S, Utrecht University).

Weber, C., Gebhardt, B., Schuler, A., Schulze, Th., Fahl, U., Voss, A., Perrels, A., van Arkel, W., Pellekaan, W., O'Connor, M., Schenk, E. \& Ryan, G. (1996) Consumers' Lifestyles and Pollutants Emissions (Stuttgart, IER, University of Stuttgart).

Weber, C. \& Schnabl, H. (1998) Environmentally important intersectoral flows: Insights from main contributions identification and minimal flow analysis, Economic Systems Research, 10, pp. 337-356.

Wilting, H. C. (1996) An Energy Perspective on Economic Activities, PhD Thesis, University of Groningen.

Wilting, H. C., Biesiot, W. \& Moll, H. C. (1998) An input-output based methodology for the evaluation of technological and demand-side energy conservation options, paper presented at the Twelfth International Conference on Input-Output Techniques, New York, May. 